Network Working Group

Request for Comments: 208

NIC: 7181

Categories: B.1, C.2

Updates: none

obsoletes: none
A. McKenzie

Bolt Beranek and Newman

9 August 1971

\title{
ADDRESS TABLES
}

Attached is a copy of a revision to Appendix A of BBN Report No. 1822; the revised version of the Appendix is our first attempt to make the list of sites attached to the ARPA Network prospective rather than retrospective. We are adopting this approach because of the large number of sites scheduled for attachment in the near future, and because many Hosts apparently require a site's address to be in some local table before their NCPs will permit communication with the site. Therefore, we urge such Hosts to add the new sites to their lists of addresses as soon as possible. Also, please note the address change which will be made at BBN on exactly september first.

Incidentally, it seems to us that it is irrational for an NCP to discard otherwise valid messages, simply because the sender's address doesn't appear in a local table. Similarly, it seems almost as irrational for an NCP to prevent a local user from trying to communicate with a remote site, the address of which is known to the user but not stored in the $\mathrm{NCP}^{\prime} \mathrm{s}$ tables. 
APPENDIX A

IMP AND HOST SITE IDENTIFICATION

Bit 9-16 of the leader of most Host-to-IMP or IMP-to-Host messages define a network address related to the message (these bits are not meaningful for message types 1, 2, and 4). In a Host-to-IMP message the network address identifies a particular Host to which the message should be delivered. In an IMP-to-Host message the network address identifies the Host from which the message originated.

A network address consists of six bits (bits 11-16 of the leader) which specify an IMP number, preceded by two bits (bits 9-10 of the leader) which specify the Host number of a particular Host connected to that IMP. The table below gives the decimal values of IMP number, Host number, and network address for each Host currently connected to the ARPA Network or scheduled for connection in the near future. Scheduled installation dates are also shown for Hosts not currently connected; these dates, however, are subject to change without notice.

\begin{tabular}{|c|c|c|c|c|c|}
\hline IMP & SITE & HOST & & NETWORK & SCHEDULED \\
\hline NUMBER & NAME & NUMBER & HOST & ADDRESS & INSTALLATION \\
\hline------ & ---- & ------ & ---- & ------- & --------- \\
\hline \multirow[t]{2}{*}{1} & UCLA & 0 & SIGMA-7 & 1 & \\
\hline & & 1 & IBM $360 / 91$ & 65 & \\
\hline \multirow[t]{2}{*}{2} & SRI & 0 & $\mathrm{PDP}-10$ (NIC) & 2 & \\
\hline & & 1 & $\mathrm{PDP}-10 \quad(\mathrm{Al})$ & 66 & \\
\hline 3 & UCSB & 0 & IBM $360 / 75$ & 3 & \\
\hline 4 & UTAH & 0 & PDP-10 & 4 & \\
\hline \multirow[t]{3}{*}{5} & $\mathrm{BBN}$ & 0 & $\mathrm{DDP}-516$ & ) & See Note 1 \\
\hline & & 1 & $P D P-10 \quad(A)$ & 69 & \\
\hline & & 2 & $\mathrm{PDP}-10 \quad(\mathrm{~B})$ & 133 & \\
\hline
\end{tabular}

Note 1: Prior to September 1, 1971 the BBN PDP-10 (A) will be Host number 0 (network address 5) and the BBN DDP-516 will be Host number 1 (network address 69). The address change is to be made during the day on $9 / 1 / 71$. 


\begin{tabular}{|c|c|c|c|c|c|}
\hline IMP & SITE & HOST & & NETWORK & SCHEDULE \\
\hline NUMBER & NAME & NUMBER & HOST & ADDRESS & INSTALLATION \\
\hline------ & ---- & ------ & ---- & ------- & ------------ \\
\hline \multirow[t]{2}{*}{6} & $\mathrm{MIT}$ & 0 & Honeywell 645 & 6 & \\
\hline & & 1 & $\mathrm{PDP}-10$ & 70 & \\
\hline \multirow[t]{2}{*}{7} & RAND & O & $360 / 65$ & 7 & \\
\hline & & 1 & $\mathrm{PDP}-10$ & 71 & \\
\hline 8 & $\mathrm{SDC}$ & O & IBM $360 / 75$ & 8 & \\
\hline \multirow[t]{3}{*}{9} & HARVARD & O & $\mathrm{PDP}-10$ & 9 & \\
\hline & & 1 & $\mathrm{PDP}-1$ & 73 & \\
\hline & & 2 & $\mathrm{PDP}-11$ & 137 & \\
\hline \multirow[t]{2}{*}{10} & LINCOLN & O & IBM $360 / 67$ & 10 & \\
\hline & & 1 & $\mathrm{TX} 2$ & 74 & \\
\hline 11 & STANFORD & O & $\mathrm{PDP}-10$ & 11 & \\
\hline 12 & ILLINOIS & O & $\mathrm{PDP}-11$ & 12 & \\
\hline 13 & CASE & O & $\mathrm{PDP}-10$ & 13 & \\
\hline 14 & CARNEGIE & O & $\mathrm{PDP}-10$ & 14 & \\
\hline 15 & PAOLI & O & B 6500 & 15 & \\
\hline \multirow[t]{2}{*}{16} & NASA/AMES & O & IBM $360 / 67$ & 16 & $8 / 3 / 71$ \\
\hline & & 2 & TIP & 144 & \\
\hline 17 & MITRE & 2 & TIP & 145 & $8 / 31 / 71$ \\
\hline \multirow[t]{2}{*}{18} & RADC & O & H $635 / 645$ & 18 & $10 / 5 / 71$ \\
\hline & & 2 & $\operatorname{TIP}$ & 146 & \\
\hline 19 & NBS & O & $\mathrm{PDP}-11$ & 19 & $11 / 2 / 71$ \\
\hline 20 & ETAC & 2 & TIP & 148 & $11 / 30 / 71$ \\
\hline 21 & TINKER & O & 418 III & 21 & $1 / 4 / 71$ \\
\hline 22 & MCCLELLAN & O & 418 III & 22 & $2 / 1 / 72$ \\
\hline \multirow[t]{2}{*}{23} & USC & 0 & IBM $360 / 44$ & 23 & $2 / 29 / 72$ \\
\hline & & 2 & TIP & 151 & \\
\hline 24 & GWC & 2 & TIP & 152 & $3 / 14 / 72$ \\
\hline \multirow[t]{2}{*}{25} & NCAR & O & CDC 7600 & 25 & $3 / 28 / 72$ \\
\hline & & 2 & TIP & 153 & \\
\hline 30 & $\mathrm{BBN} / \mathrm{TIP}$ & 2 & TIP & 158 & \\
\hline
\end{tabular}

